\title{
Comparison of the incidence of diarrhoeal diseases in two regions of the Aral Sea area, Uzbekistan
}

\author{
S. Herbst ${ }^{1,2}$, T. Kistemann ${ }^{1}, \&$ D. Fayzieva ${ }^{3}$ \\ ${ }^{1}$ Section for Public Health and Medical Geography at the Institute for \\ Hygiene and Public Health,Bonn University, Germany. \\ ${ }^{2}$ Center for Development Research (ZEF), Bonn University, Germany. \\ ${ }^{3}$ Institute for Water Problems,Academy of Sciences, Tashkent, \\ Uzbekistan.
}

\begin{abstract}
To investigate differences in the occurrence of gastrointestinal diseases in two regions affected by the Aral Sea disaster and with difficult drinking water conditions, crude incidence rates and microbial water quality were compared. In the more developed urban areas of Khorezm and Karakalpakstan, centralized drinking water supply is available. Residents of rural areas predominantly use ground water for drinking water purposes. Whereas microbial drinking water quality in Khorezm is still deteriorating it seems to be improving in Karakalpakstan. The microbial quality of the drinking water in Khorezm has deteriorated most notably between 1999 and 2001. During this period up to $61.8 \%$ of the samples exceed the critical limit for the Total Microbial Count (TMC) and even more than $80 \%$ the critical limit for the parameter coli index, which proves faecal contamination.

Incidence rates for all diarrhoeal diseases as well as hepatitis A are declining substantially over the last decade. Given the fact that both regions are known to have serious drinking water problems, these tendencies are questionable. Especially in rural areas these changes are more likely to be underreporting due to the worsening socio-economic situation, than changing disease occurrences.
\end{abstract}




\section{Environmental Health Risk}

\section{Introduction}

It is well-known that the drying up of the Aral Sea has led to an ecological and economic disaster in Central Asia. A total of 35 million people are living in the Aral Sea basin. Four million people are directly affected by this man-made catastrophe, which causes serious health effects. The two most affected regions are situated south of the Aral Sea, namely Khorezm and Karakalpakstan. Between mid 2000 and 2001 the worst drought in one hundred years worsened the human and socio-economic conditions in these regions dramatically. Problems concerning the quality of drinking water and the incidence of waterborne diseases are various and tremendous [1].

In 2001, the drinking water supply coverage for the rural population of Uzbekistan was $72.3 \%$ compared to $67.7 \%$ for Khorezm and $68.6 \%$ for Karakalpakstan, respectively. About $51 \%$ of all households in Khorezm and Karakalpakstan extract their drinking water either from open wells or shallow boreholes, which are often faecally contaminated. The microbial pollution of ground water is a consequence of the lack of sanitation and inefficient irrigation methods. Inefficient drainage methods result in a rise in the groundwater level, which is very close to the surface and washes up the latrines. Later on the unsanitary groundwater is used as drinking water. In general those conditions would suggest causing a high incidence of waterborne gastrointestinal diseases.

\section{Data and methods}

In spring 2002, secondary raw data on microbial drinking water quality, demography and specific infectious diseases were collected during field trips to Nukus, Karakalpakstan and Urgench, Khorezm. The raw data were obtained for the period between 1991 and 2001 from the local Province Centre of Sanitation and Epidemiology in Urgench and the Republican Centre of Sanitation and Epidemiology in Nukus. Data on the microbial drinking water quality for Karakalpakstan were only available for the period between 1997 and 2001.

Drinking water sampling and proceeding of the samples, according to the Russian standardised methods from 1982 [2], is carried out by the Centres of Sanitation and Epidemiology (SES). Due to this regulation drinking water in the public supply network is monitored for Total Microbial Count (TMC), coli index and coli titre. The parameter TMC is comparable with the EU Colony Count at $36^{\circ} \mathrm{C}$, the critical limit in EU as well as in Uzbekistan is 100 Colony Forming Units (CFU) per milli-litre. The procedure conducted to obtain the coli index is a semi-quantitative method to determine the number of coli bacteria, similar to the Most Probable Number (MPN) method. The coli index is a statistical approximation, which expresses the most likely number of coli bacteria contained in one litre of drinking water. In practice this means that in one litre of drinking water e.g. with a coli index of 3 between 0.5 and 13 coli bacteria can be present [3]. The coli titre is the amount of water which is likely to contain one 
coli bacterium; it is calculated on the basis of the respective coli index result. According to the GOST 2874-82 the critical limits are 3 and 333, respectively.

For drinking water samples taken from hand pumps, wells or surface water the parameters TMC and coli titre are given for Khorezm. The critical limit for the coli titre of drinking water obtained from hand pumps and wells and for surface water is 111 and 11.1, respectively. Whereas in Karakalpakstan for all types of drinking water sources TMC and coli index with the critical limit of 3 is applied.

Faecally contaminated drinking water sources are a possible transmission route for diseases such as hepatitis A, typhoid fever and shigellosis [4]. Shigellosis also known as bacillary dysentery occurs due to infection with Shigella spp. To assess the occurrence of those infectious diseases their cumulative incidence rates for the period between 1991 and 2001 were calculated. The cumulative incidence rate is a measure for the risk of individuals in a population of acquiring the disease during a specified period. For better comparability of the incidences, additionally the incidences for the Republic of Uzbekistan, as received from the Ministry of Health of the Republic of Uzbekistan (MOH) are included.

\section{Results}

\subsection{Microbial drinking water quality}

\subsubsection{Khorezm}

In Khorezm $57 \%$ of the drinking water samples were taken from the centralized drinking water supply system in Urgench city. Only sporadic sampling was carried out in the rural areas of Urgench rayon (55 samples) other rayons or other drinking water sources of Khorezm oblast.

Regarding the results of the drinking water samples two aspects are striking. First the number of samples has decreased about by $78 \%$ during the last decade. Second the microbial quality of the drinking water has deteriorated dramatically. After a phase with moderate numbers of samples beyond the limit for TMC (1994-1996) their numbers increased substantially. Especially since the drought, which started in 1999 always more than one third of the samples, in 1999 even $61.8 \%$ percent of the drinking water samples contained more than $100 \mathrm{CFU}$ (TMC) per milli-litre. The parameters for monitoring the faecal contamination display even worse results. Coli index and coli titre also peak in 1999. But in that year more than $80 \%$ of the drinking water samples contained more than 3 coli bacteria per litre. In total in 9 out of 11 years more than $50 \%$ of the samples contained more than 3 coli bacteria per litre (Table 1).

The results of the drinking water samples taken from hand pumps and wells prove similar tendencies; their number has also decreased drastically. For the period between 1992 and 1997 the number of samples which exceed the limit is low for TMC (2.8\%). But $53.1 \%$ of samples exceed the limit for the coli titre 
156 Environmental Health Risk

Table 1: Microbial drinking water quality in Khorezm

\begin{tabular}{|c|c|c|c|c|c|c|c|}
\hline year & $\begin{array}{c}\text { no. of } \\
\text { samples }\end{array}$ & $\begin{array}{c}\text { TMC } \\
>\mathbf{1 0 0}\end{array}$ & $\mathbf{\%}$ & $\begin{array}{c}\text { coli index } \\
\mathbf{3}\end{array}$ & $\mathbf{\%}$ & $\begin{array}{c}\text { coli titre } \\
\mathbf{3 3 3}\end{array}$ & $\mathbf{\%}$ \\
\hline 1991 & 366 & 70 & 19.1 & 208 & 56.8 & 207 & 56.6 \\
\hline 1992 & 212 & 34 & 16.0 & 139 & 65.6 & 139 & 65.6 \\
\hline 1993 & 221 & 53 & 24.0 & 175 & 79.2 & 175 & 79.2 \\
\hline 1994 & 133 & 4 & 3.0 & 97 & 72.9 & 98 & 73.7 \\
\hline 1995 & 167 & 13 & 7.8 & 96 & 57.5 & 96 & 57.5 \\
\hline 1996 & 163 & 14 & 8.6 & 99 & 60.7 & 99 & 60.7 \\
\hline 1997 & 147 & 20 & 13.6 & 70 & 47.6 & 70 & 47.6 \\
\hline 1998 & 121 & 26 & 21.5 & 49 & 40.5 & 50 & 41.3 \\
\hline 1999 & 204 & 126 & 61.8 & 173 & 84.8 & 170 & 83.3 \\
\hline 2000 & 79 & 29 & 36.7 & 63 & 79.7 & 63 & 79.7 \\
\hline 2001 & 82 & 40 & 48.8 & 59 & 72.0 & 57 & 69.5 \\
\hline total & $\mathbf{1 8 9 5}$ & $\mathbf{4 2 9}$ & $\mathbf{2 2 . 6}$ & $\mathbf{1 2 2 8}$ & $\mathbf{6 4 . 8}$ & $\mathbf{1 2 2 4}$ & $\mathbf{6 4 . 6}$ \\
\hline
\end{tabular}

(111) during that period. Sampling of surface water, which is used for drinking water purposes, has very seldom been carried out. For the period between 1991 and 2001 exist only 138 sampling results of which $51.4 \%$ do not meet a TMC of 100 and even $92 \%$ exceed the limit for coli titre of 11.1 .

\subsubsection{Karakalpakstan}

In Karakalpakstan more than $40 \%$ of the drinking water samples from the public supply network were taken in Nukus rayon. The number of drinking water samples has been substantially lower than usual in 1999, when the drought started. The percentage of drinking water samples from the public supply network, which did not meet the TMC limit declined between 1999 and 2001 about 4-fold. In 1997 the coli index exceeded the critical limit in almost $50 \%$ of the samples. Since then the critical limit was always exceeded in less than $37 \%$ of the samples (Table 2). For the five year period between 1997 and 2001 in total only 24 drinking water samples from hand pumps and wells have been tested. Out of these samples $21 \%$ exceeded the critical limit for TMC and $79 \%$ the coli index of 3 . In samples taken from surface water (21), which is used for drinking water abstraction, even $57 \%$ exceeded the limit for TMC and $81 \%$ the coli index of 3 .

Table 2: Microbial drinking water quality in Karakalpakstan

\begin{tabular}{|c|c|c|c|c|c|}
\hline year & no. of samples & $\begin{array}{c}\text { TMC } \\
>\mathbf{1 0 0}\end{array}$ & $\begin{array}{c}\text { coli index } \\
\mathbf{3}\end{array}$ & $\mathbf{\%}$ \\
\hline 1997 & 66 & 13 & 19.7 & 32 & 48.5 \\
\hline 1998 & 96 & 9 & 9.4 & 13 & 13.5 \\
\hline 1999 & 32 & 6 & 18.8 & 9 & 28.1 \\
\hline 2000 & 82 & 9 & 11.0 & 30 & 36.6 \\
\hline 2001 & 68 & 3 & 4.4 & 19 & 27.9 \\
\hline total & $\mathbf{3 4 4}$ & $\mathbf{4 0}$ & $\mathbf{1 1 . 6}$ & $\mathbf{1 0 3}$ & $\mathbf{2 9 . 9}$ \\
\hline
\end{tabular}




\subsection{Diarrhoeal diseases and hepatitis $\mathbf{A}$}

The incidence for all acute intestinal infections for total Uzbekistan as well as for Khorezm and Karakalpakstan declined substantially since the independence in 1991. While the incidence for all acute intestinal infections has halved for Uzbekistan it has decreased 3-fold for Karakalpakstan and even 7-fold for Khorezm over the last decade (Table 3). During the previous five years before the independence (1986-1990) the incidence for Khorezm decreased more moderate from 1071 to 942 cases per 100,000 population.

The incidence for typhoid fever decreased for Uzbekistan from 7 to 1 per 100,000 population between 1991 and 1999. During that period for both regions the incidences were lower than those for Uzbekistan except the year 1991, where in Karakalpakstan the incidence was 7 per 100,000 population.

For Uzbekistan the incidence for dysentery halved between 1992 and 1999. It declined 3-fold for Karakalpakstan and even more than 10-fold for Khorezm during the last decade (Figure 1). Despite having registered $50 \%$ fewer cases than the average for Uzbekistan the numbers for Khorezm prove the same peak for dysentery cases in 1994. The incidence for bacillary dysentery in Khorezm oblast decreased from 12.1 to 0.6 per 100,000 population between 1997 and 2000. While the incidence for urban and rural population was similar in 1997, since 1998 the incidence rate was substantially lower for the urban population than for the rural population.

The incidence for hepatitis A also dropped substantially for Uzbekistan in general and both regions as well. Despite that fact the lower incidences for Karakalpakstan and Khorezm display the same tendencies as the numbers for Uzbekistan. In Khorezm the rural cases exceeded the urban cases for more than $50 \%$ for 1999 and 2000 . While the hepatitis A cases in both regions declined constantly the decline for Uzbekistan happened rapidly since 1997 (Figure 2).

Table 3: Incidence of all acute intestinal infections per 100,000 population

\begin{tabular}{|c|c|c|c|}
\hline & Uzbekistan & Khorezm & Karakalpakstan \\
\hline $\mathbf{1 9 9 1}$ & 576.8 & 826.5 & 476.6 \\
\hline $\mathbf{1 9 9 2}$ & 523.1 & 680.7 & 373.1 \\
\hline $\mathbf{1 9 9 3}$ & 535.7 & 592.2 & 393.5 \\
\hline $\mathbf{1 9 9 4}$ & 324.7 & 590.5 & 285.1 \\
\hline $\mathbf{1 9 9 5}$ & 267.5 & 406.9 & 255.8 \\
\hline $\mathbf{1 9 9 6}$ & 296.8 & 356.2 & 204.6 \\
\hline $\mathbf{1 9 9 7}$ & 246.4 & 336.8 & 244.1 \\
\hline $\mathbf{1 9 9 8}$ & 279.4 & 310.6 & 185.1 \\
\hline $\mathbf{1 9 9 9}$ & 225.8 & 218.6 & 160.5 \\
\hline $\mathbf{2 0 0 0}$ & - & 166.0 & 143.8 \\
\hline $\mathbf{2 0 0 1}$ & - & 118.6 & 153.2 \\
\hline
\end{tabular}


158 Environmental Health Risk

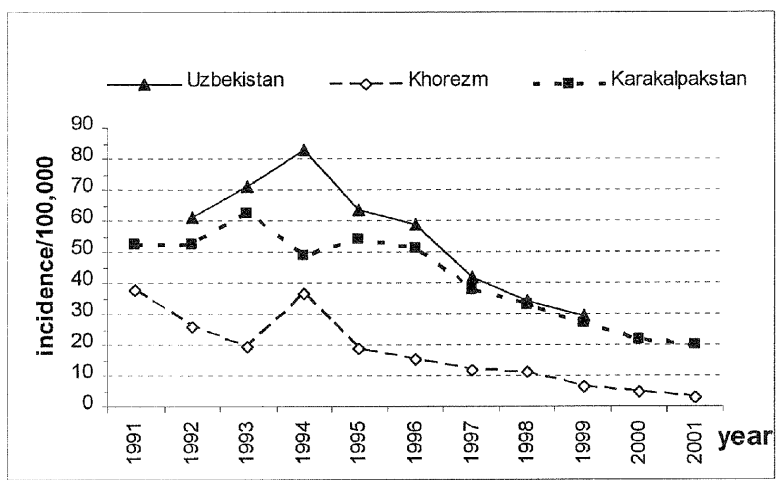

Figure 1: Incidence of dysentery between 1991 and 2001

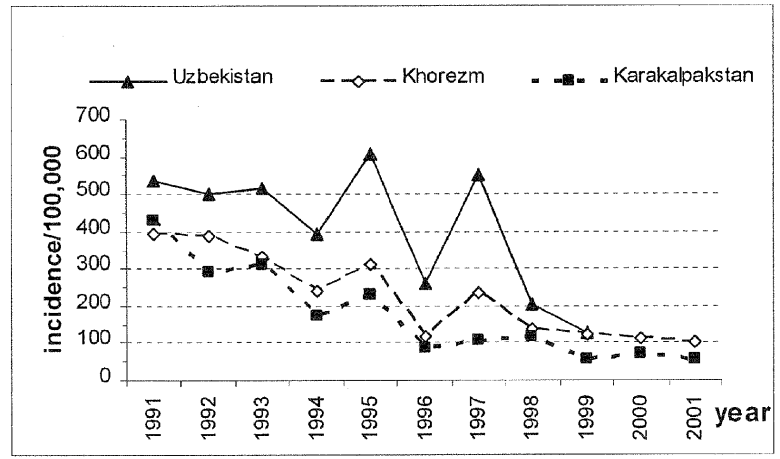

Figure 2: Incidence of hepatitis A between 1991 and 2001

\section{Discussion}

The comparison of the microbial drinking water sampling results -mainly from urban areas-shows a differing microbial drinking water quality for Khorezm and Karakalpakstan.

While the number of samples that exceed the critical limit for TMC increases starkly in Khorezm, it decreases constantly in Khorezm. In the year 2001 for Khorezm a 12-fold higher percentage of samples did not meet the limit than for Karakalpakstan.

Regarding the indicator parameter for faecal contamination for Khorezm the microbial drinking water quality deteriorated dramatically, since 1999. This is especially surprising because drinking water from the public supply network is treated and additionally chlorinated twice, since 1995. The trend for Karakalpakstan is vice versa, there the microbial drinking water quality 
improved, since 1997. For the five year period between 1997 and 2001 the total percentage of samples with a coli index higher 3 is 65 for Khorezm and 30 for Karakalpakstan.

Many waterborne outbreaks of viral hepatitis A (and E) have been reported due to faecal contamination of drinking water [5]. Because Salmonella typhi exclusively colonizes in humans its occurrence is closely associated with waste water. The transmission route is faecal-oral by contaminated food or water [6]. According to the Russian Standard Methods from 1982 the faecal contamination of drinking water is measured by the parameter coli index with the critical limit 3/L. Measured according to the WHO-Guidelines as well as to German Drinking Water Guidelines where the critical limit is $0 / 100 \mathrm{~mL}$ this contradicts the demand for save public drinking water supply. The fact that in both regions at least around $30 \%$ of the drinking water samples exceed the critical coli index limit of $3 / \mathrm{L}$, would suggest an increased risk for waterborne gastrointestinal diseases.

Parameters which are used for the measurement of drinking water quality from hand pumps and wells, as well as for surface water differ for Khorezm and Karakalpakstan. In Khorezm for water stemming from hand pumps and wells the parameter coli titre with a critical limit of 111 is used. Whereas in Karakalpakstan coli index with the critical limit of 3 is used. For surface water used for drinking water purposes in Khorezm again the coli index is used but with a critical limit of 11.1. According to the given data the drinking water monitoring in Karakalpakstan is more appropriate. Water which is used for drinking purposes always should be monitored according to critical limits for drinking water even when the water originates from other water sources like wells or surface water.

The deterioration of the microbial drinking water quality in the supply network can be caused by different reasons, which were mentioned during several expert interviews. Leakages and drinking water pipes lying alongside with sewerage system -as the situation is in both regions in general when sewerage is existent- poses a high potential for contamination of the drinking water. Illegal connections and pressure losses can also cause contamination [7]. Discontinuous water supply and insufficient water pressure in the mains - which are common in both regions- support re-growth of pathogens in the distribution system. These maintenance and operation problems are likely to be the causes of poor drinking water quality in those regions. The declining activity for the monitoring of the microbial drinking water quality is caused by budgetary constraints of the responsible institutions.

Looking at the inconsistent results which display deterioration of the microbial water quality on the one hand and decreasing incidences of gastrointestinal diseases on the other hand; these outcomes have to be taken carefully. These changes in the registration may partly go due to changing disease rates, and partly due to a lack of registration caused by the development of the Uzbek health system and its impact on health behaviour.

In-patient care admissions have decreased from 24 in 1991 to 13.3 consultations per 100 population in 2000 in Uzbekistan. The total health 
expenditure as per cent of GDP has halved from 6 to 3 between 1991 and 2000. The data for total health expenditure measured in purchasing power parity conversation factor (ppp \$) per capita show the same stark decline. In 1991 the total health expenditure was $165 \mathrm{ppp} \$$ per capita, whereas it was only $65 \mathrm{ppp} \$$ per capita in 2000. In-patient care admissions have decreased from 24 in 1991 to 13.3 consultancies per 100 population in 2000 in Uzbekistan [8].

Falkingham [9] proved the same health-economic development for Kyrgyzstan and concluded that because of charging, patients consultations have decreased significantly. This tendency is even more valid for rural and poor residents. "Those from the poorest group are less likely to seek help from the medical services..." [9]. These facts may help understanding the decreasing incidences of gastrointestinal diseases in general and the changing share of urban and rural population. This may also explain the increase of the registration of cardio vascular diseases. Living under such difficult economic circumstances, makes it more likely that people seek health consultations only in severe cases, which result in a biased registration of gastrointestinal diseases. Discrepancies between official registration and actual incidences are also known from other countries $[10,11]$. However, these discrepancies need to be reconciled.

From mid of May till the end of July 2003, a household survey and microbial testing of different drinking water sources was conducted to investigate these relationships further.

\section{Conclusions}

Gastrointestinal diseases seem to be underreported in both regions of the Aral Sea area which have been included in this investigation. To assess possible drinking water related disease outbreaks the monitoring of the microbial drinking water quality should be extended and adapted to international standards. Baseline data on the actual incidences of gastrointestinal, especially waterborne diarrhoeal diseases for the assessment of the health situation and health-economic burden of the population are urgently needed.

\section{Acknowledgements}

A GIS-supported investigation of "Drinking Water Supply and Water-Related Infectious Diseases" is being carried out by Center for Development Research (ZEF), in close collaboration with the Government of Uzbekistan, in the framework of the project "Economic and Ecological Restructuring of Land and Water Use in the Khorezm Region (Uzbekistan)" funded by the German Ministry for Education and Research (BMBF). The contents of this manuscript are solely the responsibility of the authors and do not necessarily represent the official views of ZEF and BMBF. 


\section{References}

[1] Semenza J.C., Roberts, L., Henderson, A., Bogan, J. \& Rubin, C.H., Water Distribution System and Diarrheal Disease transmission: a Case Study in Uzbekistan. American Journal of Tropical Medicine \& Hygiene, 59(6), pp. 941-946, 1998.

[2] State Committee for Standardization, Drinking Water, Methods of Analysis, State Standards of the Union of the S.S.R. (GOST 2874-82), Moscow 1984.

[3] Daubner, I., Mikrobiologie des Wassers, Akademie-Verlag,: Berlin, pp. 257$261,1984$.

[4] Hunter, P., Waterborne disease: epidemiology and ecology, John Wiley \& Sons: Chichester, New York, Weinheim, 1997.

[5] Hau, C.H., Tran, T.H., Hien, T.T., Ha, B.K., Tien, N.T., Khiem, H.B., Sac,P.K., Nhung, V.T., Larasati, R.P., Laras, K., Putri, M.P., Doss, R., Hyams, K.C. \& Corwin, A.L., Prevalence of enteric hepatitis A and E viruses in the Mekong river delta region of Vietnam. American Journal of Tropical Medicine and Hygiene, 60(2), pp. 277-280, 1999.

[6] Hunter, P., Waterborne disease: epidemiology and ecology, John Wiley \& Sons: Chichester, New York, Weinheim, pp. 116-123, 1997.

[7] Moe, C. L., Prospective studies of endemic waterborne disease in developing countries (Chapter 19). Drinking water and infectious disease - Establishing the links, eds. P. R. Hunter, M. Waite \& E. Ronchi, CRC Press: London, New York and Washington, D.C., pp. 197-206, 2002.

[8] WHO Regional Office for Europe, European health for all database, 2002.

[9] Falkingham, J., "Barriers to access?". eurohealth, 4(6), pp. 68-71, 1998/1999.

[10]Egorov, A.I., Naumova, E.N., Tereschenko, A.A., Kislitsin, V.A. \& Ford, T.E., Daily variations in effluent water turbidity and diarrhoeal illness in a Russian city. International Journal of Environmental Health Research, 13, pp. 81-94, 2003.

[11]Isenbarger, D.W., Hien H.T., Ha, T.T., Bodhidatta, L. \& Cam, P.D.,Prospective study of the incidence of diarrhoea and prevalence of bacterial pathogens in a cohort of Vietnamese children along the Red River. Epidemiology \& Infection, 127, pp. 236-94, 2001. 
